Journal of

Applied

Crystallography

ISSN 0021-8898

Received 17 August 1999

Accepted 6 December 1999

(C) 2000 International Union of Crystallography Printed in Great Britain - all rights reserved

\section{Crystallization bench}

\author{
B. Cabric ${ }^{\mathrm{a} *}$ and T. Pavlovic ${ }^{\mathrm{b}}$
}

\author{
${ }^{\mathbf{a}}$ Faculty of Sciences, PO Box 60, 34000 Kragujevac, Yugoslavia, and ${ }^{\mathbf{b}}$ Faculty of Sciences, PO Box \\ 92, 18000 Nis, Yugoslavia. Correspondence e-mail: bcabric@knez.uis.kg.ac.yu
}

\section{Introduction}

Most crystallizable substances occur in nature in polycrystalline forms. Single crystals of macroscopic size are rare because special conditions are required for their formation. At present they are produced in laboratories since they are used in many scientific investigations and technical applications. Preparation of single crystals can in principle be achieved in three ways: by crystallization from the solid, the liquid or the gas phase. A number of methods have been developed to grow single crystals (Laudise, 1970; Wilke, 1977; Wilke \& Bohm, 1988). Selection of the most suitable method for the preparation of single crystals of a particular substance depends not only on the nature and physico-chemical properties of the substance used, but also on the intended application, desired quality and available laboratory equipment. The preparation of single crystals from a melt, i.e. monocomponent (pure) liquid phase, is carried out by controlled freezing (Laudise, 1970). In comparison to other techniques, it is a simple and easily controlled process. In addition, the rate of single-crystal growth from a melt can be much higher than when using other techniques. It is also easier to control the crystal purity using this method. However, it cannot be used for a material that decomposes before it melts, or that has a vapour pressure that is too high at the melting point (Laudise, 1970).

As part of a larger project on the preparation of single crystals of a family of compounds newly synthesized in a laboratory tube furnace (Filipovic et al., 1998), we have constructed and installed an air cooler for simultaneous regulation of different crystallization rates in a series (family) of Tamman test tubes (Fig. 1), which is suitable for school laboratory work.

\section{Crystallization procedure}

The procedure involves first an increase of the voltage until the substances in the Tamman test tubes are completely melted. Then, while a constant furnace voltage is maintained, air is allowed to flow through the cooler. At the beginning, the air flow is weak, but it gradually increases so that the solidi- fication front starting at the bottom of the test tubes moves upwards until it reaches the surface of the melt after several hours.

On account of the slight degree of supercooling and the small volume of the supercooled melt at the bottom of the Tamman test tube, only a few crystal seeds will be formed. The seeds growing in the direction of the capillary walls sooner or later end their growth at the capillary walls (crystals growing in the $A a$ and $C c$ directions in Fig. 2). Only the seed which grows along the capillary axis, $B b$, will dominate the interface. When it leaves the capillary tubing, it spreads over the whole cross section of the tube, producing a single crystal.

The crystallization rate interval (Cabric et al., 1988, 1990) in each test tube is regulated by the cross section of the air flow (a), i.e. by translation movement of the test-tube rings (Fig 1). The temperature gradient is regulated by distance $(b)$. Different temperature gradients in the test tubes can be simultaneously regulated using an inclined cooler, i.e. 'inclined cold bench'. By varying the internal and external cooler shape and dimensions, a family of coolers can be modelled for different intervals of temperature gradients and crystallization rates. Different crystallization fronts and rates in crucible columns can also be regulated below the cooler so that crystallization starts on the surface of the melt. Crystal growth then occurs downward from the lower interface of the floating

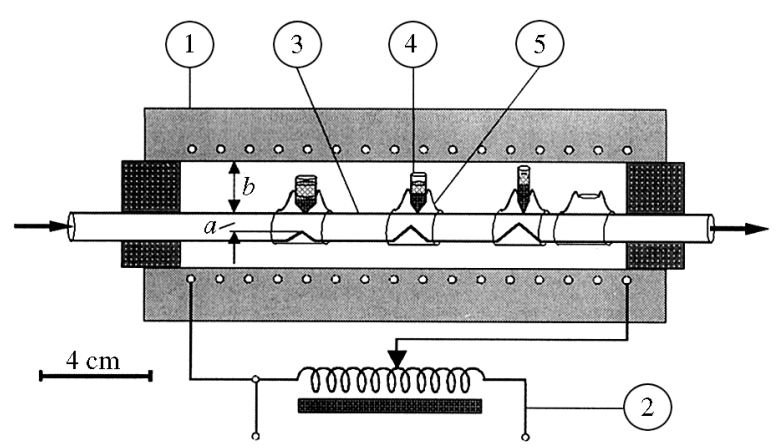

Figure 1

Crystallization regulation in a tube furnace. (1) Electroresistant tube furnace. (2) Continuously changeable transformer. (3) Air cooler ('cold bench'). (4) Tamman test tubes. (5) Rings. 


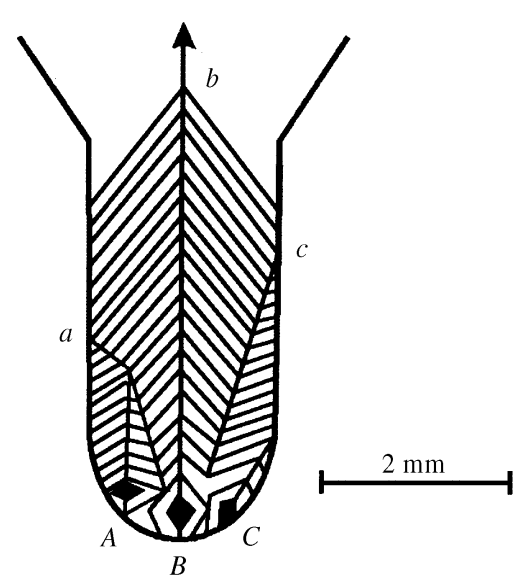

Figure 2

The beginning of crystallization at the bottom of the capillary tube (the bottom of the Tamman test tube). Only crystals growing in the $B b$ direction will continue into the main part of the tube.

crystal. Tamman test tubes of various shapes and dimensions [a family group (Laudise, 1970; Wilke, 1977; Wilke \& Bohm, 1988)] can be mounted on test-tube rings and thus simultaneously tested. A cooler with several Tamman test tubes on one ring can be installed ('crystallization tree') in a tube furnace in a vertical position. The test tubes and cooler can be twisted into the shapes of letters ' $L$ ' and ' $U$ ', respectively ('crystallization horseshoes'), and installed in a crucible furnace. Several different coolers (several cold benches in the form of horseshoes) can be installed in a chamber furnace (i.e. 'multi-bench crystallizer'). This increases the number of simultaneous crystallization tests of different test tubes, temperature gradients, crystallization fronts, rate intervals (Cabric et al., 1988, 1990) and substances, enabling fast studies of obtaining single crystals by a modular crystallization apparatus.

The preparation of crystals of good quality, containing a low concentration of impurities and defects, requires a crystallizable substance of high purity, test tubes made of materials that do not react chemically with the melt, a high degree of temperature stabilization of the furnace, and the absence of
Table 1

Conditions for the crystallization of some substances (Wilke, 1977; Wilke \& Bohm, 1988).

\begin{tabular}{lllll}
\hline Substance & $\begin{array}{l}\text { Melting } \\
\text { temperature } \\
(\mathrm{K})\end{array}$ & $\begin{array}{l}\text { Test-tube } \\
\text { material }\end{array}$ & $\begin{array}{l}\text { Test-tube } \\
\text { diameter } \\
(\mathrm{mm})\end{array}$ & $\begin{array}{l}\text { Crystal } \\
\text { growth } \\
\text { rate } \\
\left(\mathrm{mm} \mathrm{h}^{-1}\right)\end{array}$ \\
\hline $\begin{array}{l}\text { Naphthalene, } \\
\quad \mathrm{C}_{10} \mathrm{H}_{8}\end{array}$ & 80.3 & Pyrex & $13-20$ & $1-4$ \\
$\mathrm{Sn}$ & 231.9 & Pyrex & 5 & $25-1380$ \\
$\mathrm{Bi}$ & 271.4 & Graphite pyrex & 5 & $25-1600$ \\
$\mathrm{~Pb}$ & 327.5 & Graphite & $4-5$ & $20-60$ \\
$\mathrm{Zn}$ & 419.6 & Pyrex & $5-15$ & $26-120$ \\
\hline
\end{tabular}

shocks (Tarjan \& Matrai, 1972). The conditions required to grow crystals of some example substances, which have low melting temperatures and can be used to obtain single crystals in a school laboratory, are shown in Table 1.

The authors wish to thank Eng. Milan Ristic, Technical Assistant in the Crystal Growth Laboratory of the Institute of Physics at the Faculty of Science in Kragujevac, for discussions and technical support.

\section{References}

Cabric, B., Zizic, B. \& Napijalo, M. Lj. (1988). Proceedings of the International Conference Teaching Modern Physics - Condensed Matter, pp. 382-383, edited by K. Luchner. Singapore: World Scientific.

Cabric, B., Zizic, B. \& Napijalo, M. Lj. (1990). Eur. J. Phys. 11, 233235.

Filipovic, O., Cabric, B. \& Despotovic, T. (1998). Extended Abstracts of VII Conference of the Serbian Crystallographic Society, pp. 3033. Belgrade: Serbian Crystallographic Society.

Laudise, R. A. (1970). The Growth of Single Crystals, pp. 159-172. Englewood Cliffs, NJ: Prentice-Hall.

Tarjan, I. \& Matrai, M. (1972). Laboratory Manual on Crystal Growth, pp. 221-238. Budapest: Akademiai Kiado.

Wilke, K.-Th. (1977). Virashchivanie Kristallov, pp. 258-311. Leningrad: Nedra. (In Russian.)

Wilke, K.-Th. \& Bohm, J. (1988). Kristallzuchtung, pp. 591-647. Berlin: Deutscher Verlag der Wissenschaften. 